\title{
USO PÚBLICO EM UNIDADES DE CONSERVAÇÃO DE PROTEÇÃO INTEGRAL: CONSIDERAÇÕES SOBRE IMPACTOS NA BIODIVERSIDADE
}

\author{
Jorge Antônio Lourenço Pontes ${ }^{1}$ \\ Flávio Augusto Pereira Mello
}

\section{Resumo}

As unidades de conservação (UCs) de proteção integral foram criadas com o principal objetivo de preservar o patrimônio ambiental natural que abrigam dentro de seus perímetros, em especial os elementos bióticos, havendo a possibilidade de uso público conforme condicionantes predeterminadas no plano de manejo e zoneamento estabelecido. Contudo, a procura por áreas naturais como alternativas ao lazer, sobretudo nos parques, vem aumentando com a popularização do lazer e o turismo em ambientes naturais. Se somarmos aos problemas do adensamento urbano que pressionam externamente e isolam muitas UCs, estas demandas acabam se constituindo num problema para as políticas de conservação e preservação da biodiversidade, sobretudo em países com elevada diversidade biológica. Neste sentido, as trilhas são as principais estruturas que determinam o padrão de dispersão e territorialização do uso público. Sua implantação assim como o manejo, representam diversos impactos sobre o ambiente natural especialmente sobre a fauna e a flora, tais como: a interferência no comportamento alimentar e reprodutivo de diversas espécies; a introdução de espécies exóticas; a fragmentação de hábitats e a redução, ou a extinção de populações nativas. A expansão das atividades de uso público, principalmente nos parques, pode camuflar interesses políticos e econômicos sob a alegação de sustentabilidade econômica e função social e, dependendo da forma que ocorra, pode comprometer os objetivos de preservação da biodiversidade. Através de estudos e análises de casos e de revisão bibliográfica, pode-se afirmar que a questão dos impactos do uso público em UCs no Brasil ainda necessita de pesquisas mais amplas e aprofundadas sobre a dinâmica de ocupação e de territorialização pelo uso público em áreas protegidas, sobretudo, no quesito das relações entre os usuários formais e a biota protegida, notadamente àquelas que podem possuir grande relevância ecológica para a gestão destas áreas.

Palavras-chave: Uso público; biodiversidade; unidades de conservação; impactos

\section{Resumen}

Unidades de Conservación (UC) de protección integral se crearon con el objetivo principal de preservar el patrimonio ambiental natural abrigan en sus perímetros, sobre todo los elementos bióticos, con la posibilidad de uso público como restricciones predeterminadas en el plan de manejo y zonificación establecido.Sin embargo, la demanda de espacios naturales como alternativa a la recreación, sobre todo en los parques, aumentan conforme el desarollo de la popularidad del ocio y el turismo en medio natural, junto al aumento de la densidad urbana que presionan desde el exterior y aísla muchas UCs, se convertendo en un problema para las políticas conservación y preservación de la biodiversidad, especialmente en países con una alta diversidad biológica. Los senderos son las principales estructuras que

\footnotetext{
${ }^{1}$ Departamento de Ciências, Faculdade de Formação de Professores, Universidade do Estado do Rio de Janeiro. Rua Francisco Portela, 524. Patronato, São Gonçalo, RJ. CEP 20.550-011. E-mail: pontesjal@ hotmail.com

${ }^{2}$ Programa de Pós-graduação em Geografia / Universidade do Estado do Rio de Janeiro. Rua São Francisco Xavier, 524, sala 4.001-2, bloco D. Maracanã, Rio de Janeiro/RJ. CEP: 20.550-013 E-mail: infotrilhas@gmail.com
} 
determinan el patrón de dispersión territorial y uso público y su ejecución, gestión puede representar varios impactos sobre el medio natural, especialmente junto a la flora y fauna; como en la interferencia en el comportamiento reproductivo y la alimentación de varias espécies, la introducción de especies exóticas, la fragmentación del hábitat y la reducción o extinción de poblaciones nativas. La interpretación generalizada de que las unidades de conservación de la categoría de parque como el espacio principal para el cumplimiento de la función social, em verdade distorsionan la razon primera de su creación, ya que esta es una función secundaria ala conservacion, pero agravada por los intereses socioeconómicos y políticos, disfrazados bajo la argumentación de sostenibilidad y función económica y social. A través del estudio y análisis de casos y revisión de la literatura, podemos decir que el tema de los impactos del uso público de las unidades de conservación en Brasil todavía necesita de estudios más amplios y profundos, no sólo acerca de la dinámica de ocupación de territorios por el uso público em áreas protegidas, pero sobre todo acerca de la relación entre los usuarios formales y la biota protegida, especialmente aquellas que pueden tener una gran relevancia para la gestión ecológica de estas áreas.

Palabras clave: Uso publico; biodiversidad; areas protegidas; impactos

\section{Introdução}

De acordo com o Diagnóstico da Visitação em Parques Nacionais e Estaduais (BRASIL.MMA, 2009) em análise da visitação em 37 parques nacionais e 55 parques estaduais em 17 estados, as atividades mais usuais nestas unidades são caminhadas de um dia $(22,4 \%)$ e com pernoite $(7,8 \%)$ totalizando $30,2 \%$ do total pesquisado, banho $(19,0 \%)$, ciclismo $(9,3 \%)$ e escalada $(5,0 \%)$ aparecem a seguir. Se for considerado que a prática de escalada também utiliza trilhas para acesso às vias, pode-se chegar a 35,2\% de atividades em trilhas por pedestres. Tal cenário se repete na análise do perfil de atividades percebidas nos parques estaduais onde as caminhadas de um dia totalizaram $23,3 \%$ e as caminhadas com pernoite $6 \%$, perfazendo $29,3 \%$, seguidas de banho $(14,0 \%)$, ciclismo $(9,3 \%)$ e escalada $(6,0 \%)$, o que totalizaria $29,3 \%$ de atividades em trilhas por pedestres ${ }^{3}$. Estes números não são específicos do turismo em escala local, mas ressaltam a importância da malha de trilhas na gestão do uso público em UCs, em geral. Além disso, reforça o debate sobre do mercado de turismo no Brasil em áreas naturais legalmente protegidas, principalmente da categoria parques, que vem gerando receitas de milhões de dólares (GORINI et al., 2006; BRASIL, 2008; MEDEIROS et al., 2011). Desta forma, deve-se destacar que o uso adequado dos recursos naturais, a preservação dos componentes bióticos e a integração do visitante com a natureza, são objetivos previstos na Lei Federal 9.985/2000 que instituiu o Sistema Nacional de Unidades de Conservação (BRASIL, 2000; EAGLES et al., 2002; GATTI et al., 2003; GANEM, 2010).

Por definição áreas abertas à visitação são consideradas zonas de sacrifício, onde o zoneamento territorial-ambiental prevê que podem ter seu ambiente alterado dentro de parâmetros pré-determinados. Outras áreas, por sua vez, privilegiam a conservação ou a preservação de espécies in situ, buscando eliminar ou diminuir as interferências antrópicas e,

\footnotetext{
3 Deve-se considerar que estes dados são de 2009 e muitos parques estaduais e federais foram criados posteriormente. Destaca-se ainda que o Estado do Rio de Janeiro não enviou dados à pesquisa.
} 
para tanto, podem ser isoladas ou dotadas de maior controle e qualificação do fluxo de visitantes. Deste modo, o adequado zoneamento e sua observância são fundamentais para a conciliação da preservação ou conservação de espécies, hábitats e paisagens dentre outras e o uso público, pois o uso inadequado destas áreas pode decorrer da ausência ou incapacidade do gestor em seguir as abordagens metodológicas previstas nos planos de manejo e de outros instrumentos de ação para as áreas naturais protegidas (BRASIL, 1994; BRAUN, 1995; DOUROJEANNI, 2003; PONTES et al., 2003; PONTES, 2006; SILVA, 2011).

Embora as metodologias consideradas para elaboração de planos de manejo estabeleçam diferentes graduações de uso (das mais restritivas as mais abertas), dada à complexidade envolvida nos diagnósticos ambientais, estes, em geral, são derivados de dados secundários, extrapolações biogeográficas, levantamentos expeditos, consultas e entrevistas junto aos diferentes atores sociais envolvidos. Contudo, não raramente são insuficientes para a tomada de decisão de gestão mais precisa; o que implica no compreensível uso regular do Princípio da Precaução por gestores, técnicos e pesquisadores, na proteção do patrimônio natural protegido muitas vezes desconhecido e sobre os quais respondem legalmente. Para diversos autores (DOUROJEANNI, 2002; DOUROJEANNI e PÁDUA, 2001, apud ZELLER, 2008), as fragilidades dos planos de manejo decorrem de desvios nos processos de elaboração conduzidos por empresas de consultoria que possuem pouca familiaridade com a rotina das UCs, dificultando o estabelecimento de prioridades para a elaboração de planos "secundários" com enfoques mais direcionados, conforme Zeller (2008). O autor ainda reforça que as informações de diagnóstico, em geral, não atendem às demandas dos técnicos para idealizar e realizar ações de conservação. Em análise de oito planos de manejo de parques nacionais do Sul e Sudeste do Brasil, destaca que os objetivos de manejo e os zoneamentos elencados nos planos, possuem pouca ou nenhuma aplicação prática, sendo "subaproveitados" até no planejamento. Considera ainda que o "padrão é de que a execução dos planos depende de mais e mais estudos, do ingresso de funcionários e de verbas consideráveis, entre outras condições que não combinam com a realidade dos parques e do Estado".

Deste modo, o presente artigo busca afirmar que a questão dos impactos da visitação em UCs no Brasil ainda necessita de pesquisas mais amplas e aprofundadas sobre a dinâmica de ocupação e de territorialização pelo uso público em áreas protegidas quando confrontada com habitats e áreas de uso da biota protegida, principalmente àquelas de maior relevância ecológica para a gestão destas áreas.

\section{Uso público e trilhas}

Em termos de Ecologia da Paisagem, estruturalmente a trilha é um corredor definido a partir do corte raso da vegetação para o estabelecimento da zona de pisoteio (área útil efetivamente utilizada pelo usuário em seu deslocamento) e a área marginal de manejo, onde a vegetação é mantida controlada para evitar seu fechamento; esse conjunto compõe o que se chama de "corredor" da trilha (MELLO ; COSTA, 2012). Suas dimensões variam conforme o objetivo, perfil do visitante e zoneamento, onde as dimensões longitudinais e laterais podem significar maior ou menor "área de sacrifício" e consequentemente seu nível de influência no 
tecido florestal. Muitas vezes atravessam diferentes ambientes naturais com limiares distintos de fragilidade (ANDRADE, 2003). Para MELLO e COSTA (2012), não obstante as campanhas de conduta consciente em ambientes naturais como o "Pega Leve", a percepção dos impactos potenciais relacionados à dinâmica ecológica das trilhas no tecido florestal é bastante reduzida entre usuários em geral e, em principio, esta condição se traduz em uma experiência mais pobre com a realidade local e a consequente percepção de menor riqueza e abundância de espécies locais. Os autores reforçam que estes aspectos são mais observados em grupos cujo foco de atenção é o consumo de paisagens e oportunidades de lazer, recreação ou esportes em ambientes naturais, onde a observação da biodiversidade é eventualmente complementar, de acordo com a visão de Wearing e Neil (2001) para os quais os parques podem ser interpretados tanto como catedral, um monumento a ser apreciado e contemplado; quanto como ginásio desportivo com amplas possibilidades de atividades. Souza e NoronhaOliveira (2012) ressaltam ainda que tem prevalecido a visão antropocêntrica no que diz respeito à prática do turismo nas áreas protegidas, ao se atribuir apenas valor utilitário à natureza enquanto meio de satisfação das necessidades de recreação humana através de uma leitura obliqua da Lei Federal N. ${ }^{o}$ 9.985/2000 que instituiu o SNUC. Para os autores, a dimensão ecocêntrica é desvalorizada em função do antropocentrismo que advoga o fim da perspectiva "santuário", reforçados pela escassez conveniente de recursos financeiros que reforçam apelos "comerciais onde o turismo é então propagado como um instrumento para a resolução dos problemas financeiros das áreas naturais".

\section{Os impactos gerados pelo uso público sobre as comunidades bióticas.}

A necessidade de corte raso da vegetação para o estabelecimento da zona de pisoteio e manejo da vegetação lateral para manutenção do corredor das trilhas, per si confere a condição de fragmentação de hábitats, especialmente de micro hábitats. Desta forma, uma faixa livre de vegetação e serrapilheira, mesmo que estreita como uma trilha, pode dificultar a dispersão de pequenos animais que possuam uma reduzida capacidade de locomoção, como os anfíbios anuros que vivem na camada de serrapilheira das florestas ombrófilas (e.g., espécies das famílias Brachycephalidae e Leiuperidae), (PONTES, 2006; PONTES et al., 2010). De fato os efeitos antropogênicos diretos como o efeito de borda, a perda e fragmentação de hábitats, estão entre os principais problemas enfrentados pela fauna, levando diversas espécies ao declínio, especialmente os anfíbios (HERO; RIDGWAY, 2006). Algumas espécies de vegetais, como as orquídeas e vertebrados terrestres, especialmente pequenos anfíbios, mamíferos e aves, constituem bons bioindicadores da qualidade ambiental de uma área natural (ROCHA et al., 2003; CUNHA; FORZZA, 2007). Porém, as espécies animais não são afetadas da mesma maneira pela fragmentação de hábitats; determinados grupos têm suas populações reduzidas ou abandonam as áreas de reprodução, enquanto que outras podem ser favorecidas por estes impactos, estimulando sua reprodução com o rápido aumento populacional (GUILLAUMON; SING, 1977; ANDRADE, 2006; OLIFIERS; CERQUEIRA, 2006; PONTES, 2006).

Cabe destacar que muitos destes impactos não são percebidos por administradores e usuários, pois escapam da sua atenção. Como certas espécies animais são mais tolerantes à presença humana (SCHELHAS, 1986; PONTES, 2006), a percepção da riqueza de espécies 
locais pode estar fora da realidade. Alguns dos principais impactos sobre a fauna e flora estão relacionados com a visitação em locais destinados como balneários naturais (e.g., córregos, cachoeiras, poços de rios, praias, recifes). O uso intensivo, onde muitos dos quais estão situados ao longo de trilhas, especialmente durante os meses mais quentes, acontecem diversas alterações ambientais como o aumento da turbidez da água, a poluição por restos alimentares e protetores solares, a modificação do leito dos corpos hídricos dulcícolas e, também, a coleta de espécimes e afugentamento (REUSS-STRENZEL et al., 1997; PONTES, 2006). Muitas vezes, a falta de diagnósticos preliminares, pode expor ao impacto da visitação hábitats de espécies aquáticas raras ou pouco conhecidas que não toleram alterações da água, tais como macro invertebrados (ROQUE; TRIVINHO-STRIXINO, 2000), determinadas espécies de peixes (OYAKAWA et al., 2006) e de outros vertebrados (GARBER; BURGER, 1995; PONTES et al., 2006, 2010). Também é comum a extração de exemplares de espécies botânicas pelos visitantes de UCs, sempre sob o argumento: "vou levar uma lembrancinha do passeio", ou "tem tantas que uma não fará falta", em especial as mais procuradas são aquelas com potencial ornamental (e.g., bromélias, cactos, orquídeas). Muitas destas espécies são endêmicas e ameaçadas de extinção. Estas extrações podem dizimar populações inteiras, como no caso das orquídeas e samambaias na floresta ombrófila densa e de plantas insetívoras e velloziáceas em campos de altitude e costões. As canelas-de-ema (Velloziaceae) têm crescimento lento e vivem por décadas e, em diversos parques do estado do Rio de Janeiro e estão sendo dizimadas, como no Parque Natural Municipal da Prainha e Parque Estadual da Serra da Tiririca. Assim, para Bergallo et al. (2009) os efeitos do uso público decorrem da falta de consolidação administrativa e operacional das UCs.

O trânsito de veículos nas estradas de acesso ou naquelas que cortam parques e reservas, são fontes potenciais de impactos, contribuindo para o atropelamento de diversos animais de médio e grande porte (FARIA; MORENI, 2000; MINISTÉRIO DO MEIO AMBIENTE / IBAMA, 2000), além de destruir importantes hábitats utilizados por pequenos animais. Pode-se citar a destruição da vegetação baixa de restinga, hábitat da lagartixa-dapraia (Liolaemus lutzae Mertens, 1938) uma espécie endêmica e ameaçada de extinção no estado do Rio de Janeiro, com a ocupação desta faixa em praias por veranistas ou pelo uso de veículos como os bugres. Mesmo o uso de trilhas por pedestres pode provocar a morte de vegetais herbáceos (e.g., orquidáceas) e de pequenos vertebrados terrestres, por pisoteio, como o caso do sapinho-de-barriga-vermelha - Melanophryniscus moreirae (MIRANDARIBEIRO, 1920), no planalto do Parque Nacional do Itatiaia, RJ (CARVALHO et al., 2000; PONTES, 2006). Encontros diretos com animais de determinadas espécies ou grupos taxonômicos, como as serpentes e crocodilianos, frequentemente geram medo ou um excesso de curiosidade no visitante. Estes encontros podem levar à morte do animal ou representar risco de acidente ofídico (PONTES; ROCHA, 2008). Além disso, a constante oferta de alimento pelos visitantes durante os encontros com a fauna nativa, pode alterar o comportamento natural de muitas espécies como no caso de micos e quatis, transformando-os em "assaltantes" de turistas (GUILLAUMON; SING, 1977; PONTES, 2006). Podem ser citados ainda: 
- O uso de trilhas por caçadores, para terem acesso aos locais onde determinados animais habitam. Geralmente são trilhas muito pouco frequentadas de áreas mais afastadas das grandes unidades de conservação de proteção integral. Esta atividade ilegal provoca grandes danos às populações de animais, especialmente nos de maior porte ou de elevado valor comercial como os mamíferos e as aves (PONTES, 2006).

- O lixo gerado pela visitação e não descartado adequadamente e no tempo devido, pode trazer diversos problemas para a fauna, tais como a poluição de hábitats, a ingestão de materiais não digeríveis, como o plástico e a intoxicação alimentar. As próprias lixeiras instaladas podem vir a constituir fontes de alimento fácil de ser obtido, alterando o comportamento natural de algumas espécies e, até mesmo, se tornarem armadilhas fatais para outras (PONTES, 2006).

- Os incêndios em UCs podem estar diretamente ligados ao uso inadequado das trilhas e das demais áreas de visitação. Estes incêndios podem ter como causa as fogueiras, pontas de cigarros ou a prática de ritos com oferendas religiosas (PONTES, 2006).

- A presença de animais domésticos em UC de proteção integral, mesmo proibida por lei, tem sido observada mais frequentemente em parques próximos de áreas mais urbanizadas, especialmente cães e gatos. Em geral são levados ou abandonados pelos visitantes ou por moradores do entorno. Estas espécies podem transmitir diversas zoonoses, como a cinomose canina que pode matar cachorros-do-mato e quatis, ou se tornar predadoras de espécies silvestres nativas levando à redução de populações (HENDERSON, 1992; PONTES, 2006; PERIN, 2007).

Deve-se mencionar ainda que na elaboração dos planos de manejo das UC, especialmente em relação ao planejamento e implantação de trilhas, dados ecológicos raramente são utilizados como fundamentos determinantes, seja pela falta de informação relacionada no texto do plano ou pela ausência de diagnósticos e referências técnicas locais. Como exemplo, pode-se destacar a sinalização de trilhas que, mormente, segue padrões apenas para alertar o visitante sobre os cuidados com a segurança, os regulamentos internos ou para orientação, mas raramente trazem informações sobre as características ecológicas das espécies animais locais (GORELL, 1987; AMBIENTAL, 1996; MENEZES; CHEVALIER, 1998; OLIVEIRA; BLOOMFIELD, 1999). Em geral, o visitante encontra como forma de orientação e informação, apenas recomendações padronizadas, observadas em folders, guias e na sinalização de trilhas (EMPRESA DAS ARTES, 1999; MENEZES; CHEVALIER, 1998; PONTES, 2006; BRASIL, 2008; MMA, 2008). A maioria das trilhas utilizadas por excursionistas, mesmo dentro das UCs implantadas, carece de um sistema adequado de placas informativas e educativas, voltadas para a preservação da fauna e de um programa de monitoramento e avaliação.

As lixeiras utilizadas em áreas naturais, em geral, são modelos urbanos e que facilitam a manipulação pelos funcionários. Galões altos e sem tampas podem ser facilmente escalados durante a noite por marsupiais como os gambás, cuícas e pequenos roedores, que depois não conseguem sair (PONTES, 2006). Estes animais podem morrer por hipotermia ou afogados, se houver chuvas fortes. As lixeiras usadas em trilhas e em outros locais nas UCs devem ser projetadas para impedir o acesso de animais silvestres ao seu interior. Porém, ainda é 
praticamente inexistente este tipo de cuidado. A alteração do comportamento animal e a tolerância à presença humana, induzida pela oferta constante de alimento podem prejudicar a capacidade de um ou mais indivíduos procurar ativamente por alimentos na natureza ou de fugir diante de ameaças, facilitando a ação de caçadores (GUILLAUMON; SING, 1977; PONTES, 2006), podendo também criar problemas aos próprios visitantes, que podem ter alimentos e objetos subtraídos, como no caso de excursionistas que são abordados por grupos de quatis - Nasua nasua (Linnaeus, 1766) ou por micos - Callithrix spp. - em diversos parques federais, estaduais e naturais municipais no estado do Rio de Janeiro (e.g., Parque Nacional da Tijuca) e em outros pontos do Brasil, como no Parque Nacional do Iguaçu, Paraná. Casos similares ocorrem em parques africanos, americanos e asiáticos com espécies de primatas, felinos e ursos, inclusive com casos de visitantes feridos ou mortos, assim como os incêndios provocados por fogueiras, velas e outras ações indesejáveis nas UC que causam profundas alterações nos micro hábitats e podem destruir grandes extensões de áreas naturais. Além disso, podem destruir abrigos e ninhos e eliminar muitas formas vegetais e animais, especialmente aquelas que possuem uma menor capacidade de deslocamento como artrópodos não alados, anfíbios e lagartos (ARIANI et al., 2004; PONTES, 2006).

Não menos grave se configura ainda a presença de espécies exóticas em áreas naturais é uma preocupação constante e crescente por parte de diversos órgãos ambientais no Brasil e no mundo, inclusive pela comunidade científica internacional (HENDERSON, 1992; CORADIN, 2006; LOPES et al., 2009; SIMBERLOFF, 2010; PIMENTEL, 2011). As espécies exóticas sejam elas representantes da fauna ou da flora vêm invadindo diferentes tipos de ecossistemas aquáticos e terrestres seja por dispersão natural ou por solturas. Estas solturas, geralmente, são acidentais ou realizadas intencionalmente por pessoas sem o conhecimento de que a presença de uma espécie alóctone (espécie estranha a um hábitat ou ecossistema, podendo ser extraterritorial) pode causar grandes impactos no ambiente, especialmente nas populações de espécies autóctones (nativa de um hábitat ou ecossistema) (CORADIN, 2006; LOPES et al., 2009; SIMBERLOFF, 2010; ROCHA et al., 2011). Entretanto, vários casos de introdução de espécies exóticas em áreas naturais são consequência da ação de visitantes, que levam seus animais domésticos ou de outras espécies para o interior das áreas naturais protegidas. Muitas creem que ao deixar uma semente, plantar uma espécie frutífera, libertar uma ave, peixe ou outro animal estão colaborando com a natureza (PONTES, 2006; LOPES et al., 2009). Indivíduos de espécies exóticas, especialmente as domésticas, devem ser mantidos fora das trilhas e de outros acessos pela equipe de fiscalização e pela administração das UC. Estes competem com as espécies autóctones pelos recursos naturais, tornam-se pragas, predadores ou podem introduzir doenças nas áreas naturais (PIMENTEL, 2011). A inspeção dos veículos que entram nas áreas, o contínuo treinamento de funcionários e a adoção de programas de educação ambiental para os visitantes e para os moradores do entorno de áreas protegidas reduziriam estes impactos sobre a fauna e a flora. 


\section{Considerações finais}

$\mathrm{O}$ aumento de investimentos em recursos humanos e materiais, na fiscalização e programas de educação ambiental são de grande importância para a preservação da biodiversidade, inclusive no caso das espécies ameaçadas de extinção (BERGALLO et al., 2000, 2009). Entretanto, a consolidação de modelos de gestão orientados com mais ênfase ao papel das UCs de proteção integral, sobretudo na categoria parque, pode garantir a preservação de espécies animais e a conservação de seus hábitats estratégicos. Mesmo havendo escassez de informações ecológicas, deve-se considerar a biota como a parte mais relevante do patrimônio protegido e, consequentemente, a oportunidade de manutenção dos serviços ambientais dirigidos aos visitantes e sociedade. Neste sentido, a utilização em um contexto mais amplo da figura das "espécies-bandeira" e/ou "guarda-chuva" em campanhas, pode gerar maior conscientização e receitas para a unidade, possibilitando ainda a preservação de outras espécies associadas (LAMBECK, 1997; ROCHA et al., 2000; NUNES et al. 2007). Deste modo, o uso público mediado pelas trilhas deve ser considerado em seu planejamento, com traçados que busquem a proteção de hábitats e nichos de espécies estratégicas. Cabe destacar que a escala espaço-temporal de gestão utilizada deve considerar as diferenças entre a percepção humana, ávida de "consumo" de paisagens, e as peculiaridades da flora e fauna protegida, cuja escala pode ser bem menos ampla e mais específica. Isto é determinante da viabilidade da conservação in situ das espécies que são ativos patrimoniais da unidade. A sua presença pode fomentar o maior aprofundamento da experiência do visitante, onde o mesmo não apenas visualiza mais uma beleza cênica, mas tem a oportunidade de compreender a função ecológica das diferentes espécies dentro do ambiente natural e da importância na própria sobrevivência da espécie humana.

\section{Referências bibliográficas}

AMBIENTAL ENGENHARIA E CONSULTORIA. Projeto de sinalização ecológica (SMAC): APA do Leme. Rio de Janeiro, 1996. 24 p.

ANDRADE, W.J. Manejo de trilhas. Disponível em:

<http://geocities.yahoo.com.br/grupochaski/downloads/trilha.doc>. Acesso em: 20 ago. 2006.

ARIANI, C.V. et al. The negative effect of fire on populations of three bromeliad species at a restinga habitat in the southern state of Santa Catarina, Brazil. Vidalia, v. 2, n. 2, p. 44-48, 2004.

BERGALLO, H. G. et al. O status atual da fauna do Estado do Rio de Janeiro: considerações finais. Pp. 145-150. In: ___ (Org.). A fauna ameaçada de extinção do Estado do Rio de Janeiro. Rio de Janeiro: EdUERJ, 2000. 166 p.

. (Org.). Estratégias e ações para a conservação da biodiversidade no estado

do Rio de Janeiro. Rio de Janeiro: Instituto Biomas, 2009. 344 p.

BRASIL. Ministério do Meio Ambiente e da Amazônia Legal / IBAMA. Roteiro técnico para elaboração / revisão de planos de manejo em áreas protegidas de uso indireto. 2. vers. Brasília, 1994. 63 p.

BRASIL. LEI Federal N. ${ }^{\circ}$ 9.985/00. Sistema Nacional de Unidades de Conservação (SNUC). Diário Oficial da União, de 19/07/00. Brasília, 2000. 
BRASIL. Programa de turismo nos parques. Brasília: Ministério do Meio Ambiente / Ministério do Turismo, 2008. 49 p.

BRASIL. Diagnóstico da visitação em parques nacionais e estaduais. Brasília: Ministério do Meio Ambiente / Ministério do Turismo, 2009. 42 p.

BRAUN, R. 1995. Plano de ação emergencial do Parque Nacional da Serra dos Órgãos: Realidade ou ilusão burocrática? Rio de Janeiro, 1995. 13 p.

CARVALHO, J. L. A influência do pisoteio em algumas propriedades físicas do solo na trilha da praia do Sul do Parque Estadual da Ilha de Anchieta. In: CONGRESSO BRASILEIRO DE UNIDADES DE CONSERVAÇÃ̃O, 2., 2000, Campo Grande. Anais... Campo Grande:

Fundação O Boticário de Proteção à Natureza, 2000. v. 2, p. 306-312.

CORADIN, L. (Org.). Espécies exóticas invasoras: situação brasileira. Brasília: Ministério do Meio Ambiente. Secretaria de Biodiversidade e Florestas, 2006. 24 p.

CUNHA, M. F. B.; FORZZA, R. C. Orchidaceae no Parque Natural Municipal da Prainha, RJ, Brasil. Acta Botanica Brasilica, v. 21, n. 2, p. 383-400, 2007.

DOUROJEANNI, M. J. Análise crítica dos planos de manejo de áreas protegidas no Brasil. In: BAGER, A. (Ed.). Áreas protegidas: conservação no âmbito do Cone Sul. Pelotas, 2003. p. $1-20$.

.Vontade política para estabelecer e manejar parques. In: TERBORGH, J. et al. (Org.). Tornando os parques eficientes: estratégias para a conservação da natureza nos trópicos. Curitiba: Editora da UFPR, 2002. p. 347-362.

2001.307 p.

. ; PÁDUA, M. T. J. Biodiversidade: a hora decisiva. Curitiba: Editora da UFPR,

EAGLES, P. F. J.; MCCOOL, S. F.; HAYNES, C. D. Sustainable tourism in protected areas: Guidelines for planning and management. World Commission on Protected Areas (WCPA). Best Practice Protected Area Guidelines Series, n. 8, 2002.

EMPRESA DAS ARTES. Parques Nacionais: Brasil. Guia de Turismo Ecológico. São Paulo: Publifolha / MMA - IBAMA; Empresa das Artes Projetos e Edições Artísticas, 1999. $384 \mathrm{p}$.

FARIA, H. H. et al. Planejamento de uma trilha interpretativa e determinação de sua capacidade de carga. In: IV CONGRESSO BRASILEIRO DE DEFESA DO MEIO AMBIENTE. Rio de Janeiro: Anais... Clube de Engenharia / UFRJ, 1995. Pp. 259-274.

FARIA, H.H.; MORENI, P.D.C. Estradas em unidades de conservação: impactos e gestão no Parque Estadual do Morro do Diabo, Teodoro Sampaio, SP. Pp. 761-769. In: Anais do II Congresso Brasileiro de Unidades de Conservação, Campo Grande, 2000.

FREIXÊDAS-VIEIRA, V.M.; PASSOLD, A.J. ; MAGRO, T.C. Impactos do uso público. Um guia de campo para utilização do método VIM. Pp. 296-305. In: Anais do II Congresso Brasileiro de Unidades de Conservação, Campo Grande, 2000.

GANEM, R.S. (Org.). Conservação da biodiversidade: legislação e políticas públicas.

Brasília: Câmara dos Deputados, Ed. Câmara, 2010. Série Mmemória e análise de leis, n. 2, $437 \mathrm{p}$.

GARBER, S.D.; BURGER, J. A 20-yr study documenting the relationship between turtle decline and human recreation. Ecological Applications, 1995, v. 5, n. 4, pp. 1151-1162. 
GATTI, G.; THUELEN, V.; NUNES, M.L.; MILANO, M. Monitoramento das unidades de conservação brasileiras - o perfil do Parque Nacional da Lagoa do Peixe - avaliação 2002. Pp. 312-319. In: Anais do $\mathbf{2}^{\mathbf{0}}$. Simpósio de Áreas Protegidas: conservação no âmbito do Cone Sul, Pelotas, 2003.

GORELL, S. Walking track construction guidelines. USA: Department of Environment and Conservation New South Wales, 30 p. 1987

GORINI, A.P.F.; MENDES, E.F.; CARVALHO, D.M.P. Concessão de Serviços e Atrativos Turísticos em Áreas Naturais Protegidas. Rio de Janeiro: BNDES Setorial, 2006, n. 24, p. 171-210.

GUILLAUMON, J.R.P.; SING, J.M. Análise das trilhas de interpretação. Boletim Técnico do Instituto Florestal de São Paulo, 1977, v. 25, 57 p.

HENDERSON, R.W. Consequences of predator introductions and habitat destruction on Amphibians and Reptiles in the Post-Columbus West Indies. Caribbean Journd of Science, 1992, v. 28, n. 1-2, pp. 1-10.

HERO, J.M.; RIDGWAY, T. Declínio global de espécies. Pp. 53-90. In: ROCHA, C.F.D.; BERGALlO, H.G.; VAN SLUYS, M. \& ALVES, M.A.S. (Org.). Biologia da conservação: essências RiMa Editora, São Carlos, 2006, 582 p.

LAMBECK, R.J. Focal Species: A multi-species umbrella for nature conservation. Conservation Biology, 1997, v. 11, n. 4, pp. 849-856.

LOPES, R.M.; CORADIN, L.; POMBO V.B.; CUNHA, D.R. (Ed.). Informe sobre as espécies exóticas invasoras marinhas no Brasil. Brasília: Ministério do Meio Ambiente, Secretaria de Biodiversidade e Florestas, 2009, Série Biodiversidade, 33, 440 p.

MEDEIROS, R. et al. (Ed.). Contribuição das unidades de conservação brasileiras para a economia nacional. Brasília: UNEP-WCMC, 2011. 44 p.

MELLO, F. A. P.; COSTA, N. M. C. da . Reflexões sobre as relações entre trilhas e a biodiversidade em áreas protegidas brasileiras. In: CONGRESO DE PLANIFICACIÓN Y MANEJO SE SENDEROS DEL MERCOSUR, 1., 2012, Piriápolis ,Uruguai. Anais... Piriápolis ,Uruguai, 2012.

MENEZES, P. C.; CHEVALIER, D. R. Projeto Rede Carioca de Trilhas: sistema de sinalização de trilhas do Município do Rio de Janeiro. Rio de Janeiro: Secretaria Municipal de Meio Ambiente ; Chico Guarisa, 1998. 16 p.

MINISTÉRIO DO MEIO AMBIENTE (MMA). Ecoturismo: orientações básicas. Brasília: Ministério do Turismo, 2008. 60 p.

MINISTÉRIO DO MEIO AMBIENTE.IBAMA. Resumo executivo: plano de manejo. Parque Nacional do Iguaçu. Brasília, 2000, 31 p.

NUNES, A. L. et al. O mico-leão-dourado (Leontopitecus rosalia): um raro produto para o Ecoturismo e a conservação da mata atlântica. In: ENCONTRO INTERDISCIPLINAR DE ECOTURISMO EM UNIDADES DE CONSERVAÇÃO , 2., 2007, CONGRESSO NACIONAL DE ECOTURISMO, 6., 2007, Anais ... 2007.

OLIFIERS, N.; CERQUEIRA, R. Fragmentação de habitat: efeitos históricos e ecológicos. In: ROCHA, C. F. D. (Org.). Biologia da conservação: essências. São Carlos: RiMa Editora, 2006. $582 \mathrm{p}$. 
OLIVEIRA, R.T.; BLOOMFIELD, V.K. Trilha autoguiada: proposta de implantação e interpretação na Floresta Nacional Mário Xavier Sandra Regina da Costa. Floresta e Ambiente, v. 6, n. 1, p. 138-143, 1999.

OYAKAWA, O.T. et al. Peixes de riachos da Mata Atlântica nas Unidades de Conservação do Vale do Rio Ribeira de Iguape no Estado de São Paulo. São Paulo: Editora Neotrópica, 2006. 201 p.

PERIN, L. B. M. A ocupação de espaços pelos lagartos na restinga da praia de Itacoatiara, Niterói, RJ. 2007. 50 p. Trabalho de Conclusão de Curso (Biologia Marinha) Faculdades Integradas Maria Thereza, Niterói, RJ, 2007.

PIMENTEL, D. (Ed.). Biological invasions: Economic and environmental costs of alien plant, animal and microbe species. 2. ed. New York: Taylor \& Francis, 2011. 449 p.

PONTES, J. A. L et al. Amphibia, Anura, Leiuperidae, Physalaemus soaresi Izecksohn, 1965: New record, distribution extension and geographic distribution map. Check List, v. 6, n. 1, p. 159-161, 2010.

Hydromedusa tectifera (South american snake-necked turtle). altitudinal record. Herpetological Review, v. 37, n. 4, p. 458, 2006.

Planejamento, manejo de trilhas e impactos na fauna. In: CONGRESSO

NACIONAL DE PLANEJAMENTO E MANEJO DE TRILHAS, 1., 2006, Rio de Janeiro. Anais... Rio de janeiro: GEA/UERJ/Infotrilhas, 2006. 1 CD-ROM.

. ; FIGUEIREDO, J. P.; CECCHETTI, R. Plano diretor, um instrumento de gestão para as unidades de conservação do município do Rio de Janeiro. In: SIMPÓSIO DE ÁREAS PROTEGIDAS: CONSERVAÇÃO NO ÂMBITO DO CONE SUL, 2., 2003, Pelotas.

Anais... Pelotas, 2003. p. 236-243

. ROCHA, C.F.D. Serpentes da Serra do Mendanha, Rio de Janeiro, RJ:

Ecologia e conservação. Rio de Janeiro: Technical Books, 2008. 147 p.

.; PONTES, R.C.; SANTA-FÉ, C.P.; LIMA, V.M.; ROCHA, C.F.D. Amphibia, Anura, Leiuperidae, Physalaemus soaresi Izecksohn, 1965: New record, distribution extension and geographic distribution map. Check List, v. 6, n. 1, p. 159-161, 2010.

.ROCHA, C. F. D. O declínio das populações animais, a degradação de hábitats e as prioridades de conservação: espécies ou hábitats?. In: BERGALLO, H. G. et al. (Org.). A fauna ameaçada de extinção do Estado do Rio de Janeiro. Rio de Janeiro: EdUERJ, 2000. 166 p. p. $17-21$.

.; BERGALLO, H. G.; MAZZONI, R. Invasive vertebrates in Brazil. Pp. 53-103. In: PIMENTEL, D. (Ed.). Biological invasions: Economic and environmental costs of alien plant, animal and microbe species. 2. ed. New York: Taylor \& Francis, 2011. 449 p. ROCHA, C.F.D. et al. A biodiversidade nos grandes remanescentes florestais do Estado do Rio de Janeiro e nas restingas da Mata Atlântica. São Carlos: RiMa Editora, 2003. 146 p.

ROQUE, F. O.; TRIVINHO-STRIXINO, S. Fragmentação de hábitats nos córregos do Parque Estadual do Jaraguá (SP): possíveis impactos na riqueza de macroinvertebrados e considerações para a conservação in situ. In: CONGRESSO BRASILEIRO DE DEFESA DO MEIO AMBIENTE, 4., 2000, Rio de Janeiro. Anais... Rio de Janeiro: Clube de Engenharia, UFRJ, 2000. p. 752-760. 
SCHELHAS, J. Construção e manutenção de trilhas. In: CURSO DE TREINAMENTO E CAPACITAÇÃO EM GERENCIAMENTO DE PARQUES E OUTRAS ÁREAS

PROTEGIDAS, São Paulo, 22 nov./ 14 Dez. 1986. São Paulo: Instituto Florestal, 1986. v. 1.

SILVA, I. L. (Coord.). Plano de manejo: Parque Natural Municipal da Catacumba. Rio de Janeiro: Secretaria Municipal de Meio Ambiente ; Coordenadoria de Proteção Ambiental, 2011. $171 \mathrm{p}$.

SIMBERLOFF, D. Invasive species. In: SODHI, N. S.; EHRLICH, P. R. Conservation Biology for all. Oxford: Oxford University Press, 2010. 358 p.

SOUZA, L.H.; NORONHA-OLIVEIRA, M.V. Zoneamento turístico em Áreas Naturais Protegidas: um diálogo entre conservação, oferta de atrativos e perfil da demanda ecoturística. Revista Brasileira de Ecoturismo, São Paulo, v. 5, n. 2, p. 197-222, maio/ago.2012.

TANIZAKI-FONSECA; MOULTON, T.P. A fragmentação da Mata Atlântica no Estado do Rio de Janeiro e a perda da biodiversidade. Pp. 23-35. In: BERGALLO, H.G.; ROCHA, C.F.D.; ALVES, M.A.S. \& VAN SLUYS, M. (Org.). A fauna ameaçada de extinção do Estado do Rio de Janeiro. Rio de Janeiro: EdUERJ, 2000, 166 p. p. 23-35.

WEARING, S.; NEIL, S. Ecoturismo: impactos, potencialidades e possibilidades. Barueri: Editora Manole, 2001. 256 p.

ZELLER, R. H. Aplicabilidade dos Planos de Manejo de oito Parques Nacionais do Sul e Sudeste do Brasil. 2008. 166p. Dissertação (Mestrado em Engenharia Florestal)-

Universidade Federal do Paraná, Curitiba, 2008. 